\title{
PAPR Influence Analysis in 8QAM-OFDM Optical Access Systems
}

\author{
Wenzhe Ma, Yufeng Shao, Zhifeng Wang, Changxiang Li, Yue Zhou, Junyi Zhou \\ Faculty of Engineering, Shanghai Polytechnic University, Shanghai, China \\ Email: yfshao@sspu.edu.cn
}

Received 1 July 2016; accepted 18 August 2016; published 25 August 2016

\begin{abstract}
In this article, the peak to average power ratio (PAPR) performance of 8 quadrature amplitude modulation-orthogonal frequency division multiplexing (8QAM-OFDM) optical signals has been researched in broadband optical access system. The complementary cumulative distribution functions (CCDFs) are analyzed of two different 8QAM-OFDMsignals with 16, 32, 64, 128, 256, 512 subcarriers by simulation. The simulation results show that, with the increase of the number of subcarrier, the PAPR value becomes higher. When the numbers of subcarrier are16 and 512, the PAPR of 8QAM-OFDM optical signals are smaller than $5.2 \mathrm{~dB}$ and $5.3 \mathrm{~dB}$ respectively. Hence, the number of sub-carriers should be chosen according to practical application.
\end{abstract}

\section{Keywords}

Optical Access System, 8QAM-OFDM, Sub-Carrier, PAPR, CCDF

\section{Introduction}

With the rapid development of optical OFDM access technology, it has become one promising modulation technique [1]. OFDM has a lot of advantages, such as high spectrum efficiency, strong dispersion tolerance and small inter symbol interference (ISI). But, optical OFDM system has high peak to average power ratio (PAPR). And the system PAPR will be impacted by a different number of sub-carriers. Since the 16QAM mapping has higher complexity than 4QAM, but it has high frequency efficiency [2]-[5]. Hence, 8QAM modulation as a trade-off solution is chosen to generate OFDM signals. In this article, 8QAM-OFDM optical access system has been set up by simulation, including 8QAM-OFDMoptical signals generation, transmission and reception. The CCDF of two types of 8QAM-OFDMsignalswith 16, 32, 64, 128, 256, 512 sub-carriers are measured and analyzed.

\section{System Analysis}

OFDM is one of Multi Carrier Modulation (MCM) technology. Its principle is that the channel is divided into a number of orthogonal sub-channel, high-speed data signal is converted into low-speed parallel sub-data streams, modulated for transmission to each sub-channel. 8QAM-OFDM based system is built. Figure 1(a) and Figure 2(b) are the system block diagram in based signal transmitter and receiving end respectively. In based signal 


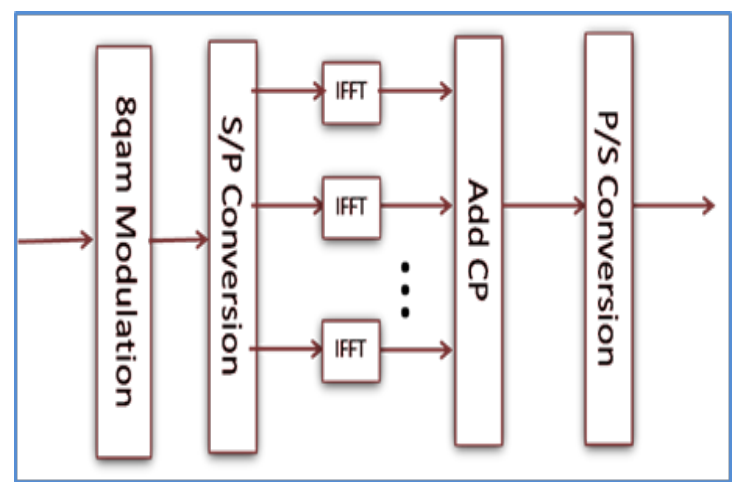

(a)

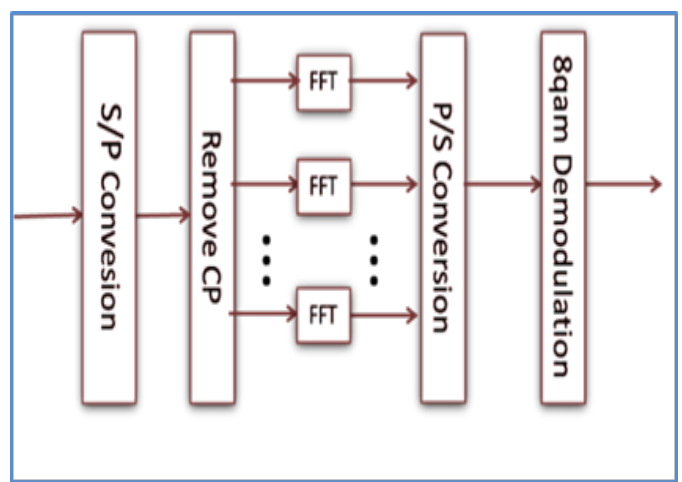

(b)

Figure 1. 8QAM-OFDM baseband (a) transmitter (b) receiver.

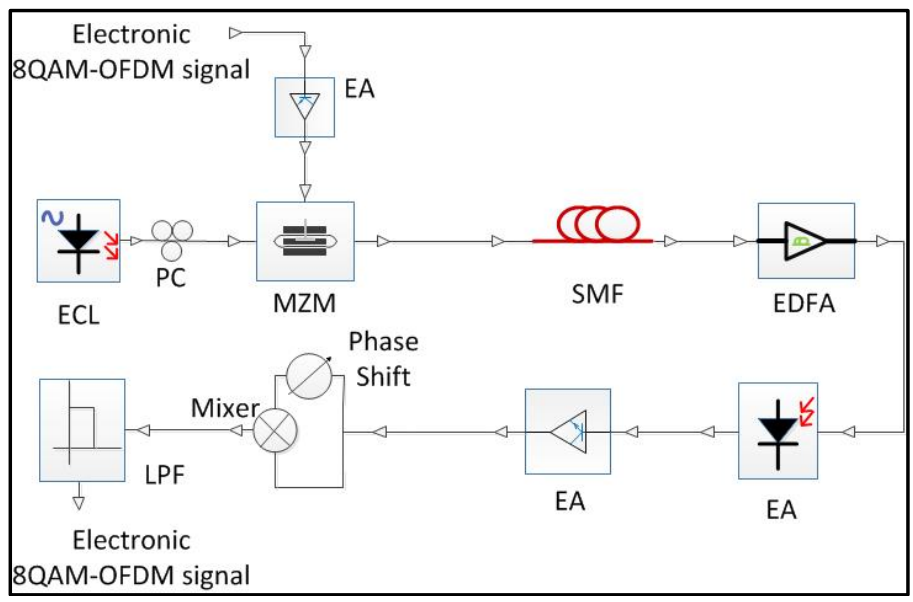

Figure 2. 8QAM-OFDM) optical access system.

transmitter end, the data is modulated by 8qam modulation. Then it is converted from serial to parallel with serial to parallel converter. Each sub-carrier is converted from the frequency domain to the time domain by inverse fast Fourier transform (IFFT). Cyclic prefix (CP) is added to each sub-carrier. After parallel to serial conversion, the data is transported in channel. In based signal receiving end, firstly symbol is converted from serial to parallel and remove CP. Each sub-carrier is converted from the time domain to the frequency domain by fast Fourier transform (FFT). After parallel to serial conversion, the data is got by 8 qam demodulation [6]-[8].

Figure 2 is $8 Q$ QAM-OFDM optical access system diagram. it is simulated by matlab. Firstly, Continuous optical carriers are transmitted by External Cavity Laser (ECL). Transmitted continuous optical carriers are modulated by Mach-Zehnder Modulator (MZM) with 8QAM-OFDM baseband signal. Modulated optical signal is transferred by single mode fiber (SMF).Optical signal is input Erbium-doped Optical Fiber Amplifier (EDFA). The output optical signals convert into the electric signal by positive intrinsic-negative photodiode (PIN PD). The electric signal is magnified by electrical amplifier (EA). The magnified signal and its phase shifter are mixed by mixer.

8QAM-OFDM baseband signal is filtered out by using a low pass filter (LPF). Another, two types of 8QAMOFDM baseband signal is used. Figure 3(a) is first class 8 qam constellation diagram. Figure 3(b) is second class 8 qam constellation diagram.

PAPR is the ratio between the amplitude peak value and the average value. After pulse shaping, the PAPR of the transmission signal is calculated by the following formula:

$$
\operatorname{PAPR}(d B)=10 \lg \frac{\max _{0 \leq t \leq T}|x(t)|^{2}}{\frac{1}{T} \int_{0}^{T}|x(t)|^{2} d t}, t \in(0, T)
$$


In Equation (1), $\mathrm{x}(\mathrm{t})$ is the transmission signal after pulse forming, $\mathrm{T}$ is the symbol period of the transmission signal. Complementary Cumulative Distribution Function (CCDF) is the statistical probability of the PAPR exceeds a certain threshold value PAPR0. Equation (2) is CCDF [9] [10]:

$$
\mathrm{CCDF}=1-\operatorname{Pr}(\mathrm{PAPR} \leq \mathrm{PAPR} 0)
$$

We analyzed the CCDF of two types 8QAM-OFDM optical access signal before and after 8QAM-OFDM signals transmitted over $10 \mathrm{~m}$ single mode fiber. Another, sub-carriers are 16, 32, 64, 128, 256 and 512. Figure 4(a) is the CCDF of two class 8QAM-OFDM optical access signal before transmission. Figure 4(b) is the CCDF of two class 8QAM-OFDM optical access signal after transmission. It is not difficult to see that, with the increase of the number of sub carriers, the PAPR becomes higher. When the number of sub carriers is 16 , the PAPR of two types of 8QAM-OFDM optical signals are smaller than $5.2 \mathrm{~dB}$. When the number of sub carriers is 512, the PAPR of two types of 8QAM-OFDM optical signals are smaller than $5.3 \mathrm{~dB}$.

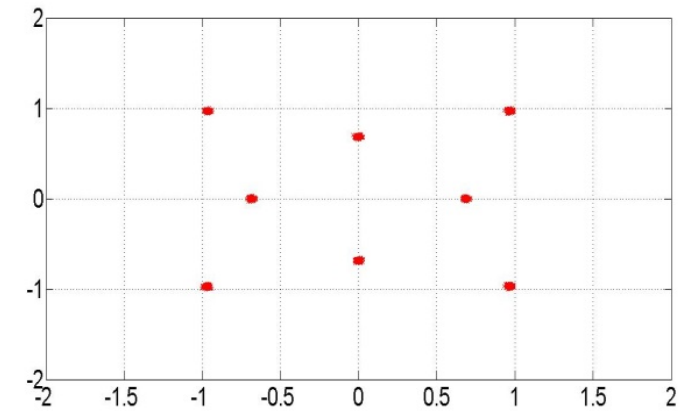

(a)

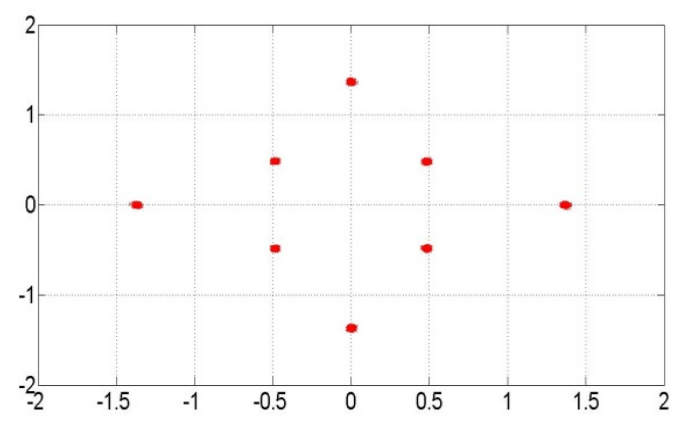

(b)

Figure 3. 8QAM-OFDM constellation diagrams of (a) first type (b) second type.

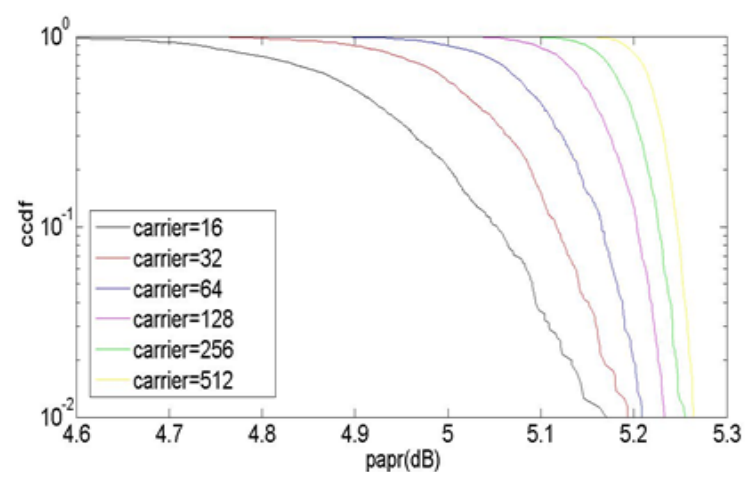

(a)

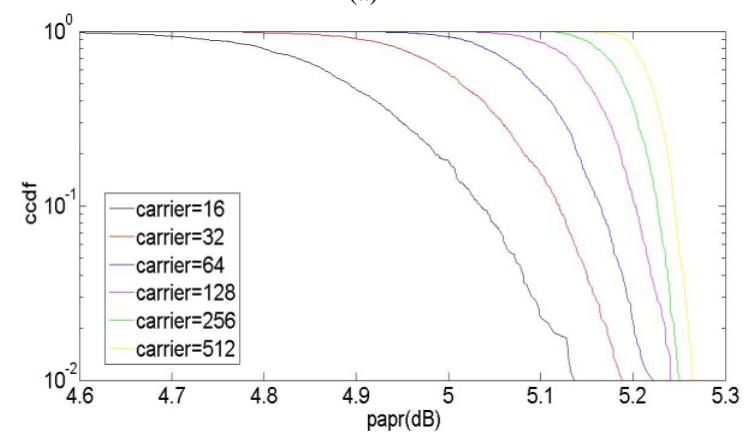

(c)

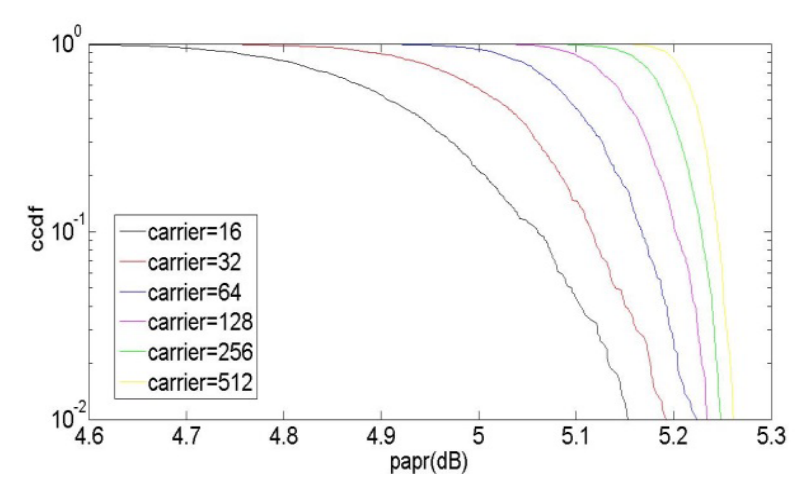

(b)

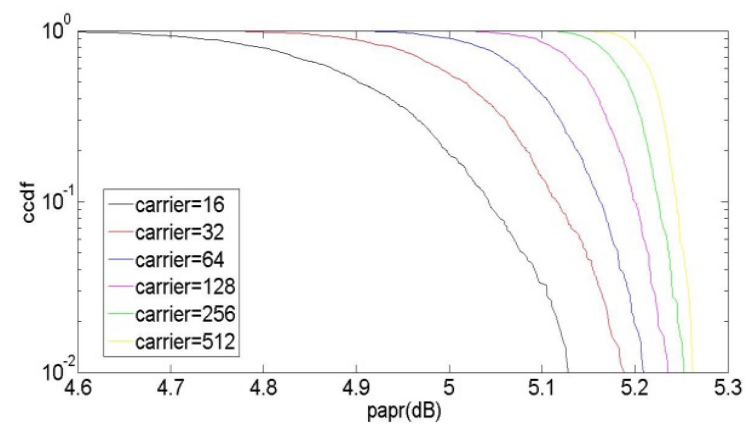

(d)

Figure 4. The CCDF of two types 8QAM-OFDM optical access signal. (a) The CCDF of first class signal before transmission (b) The CCDF of second class signal before transmission; (c) The CCDF of first class signal after transmission (d) The CCDF of second class signal after transmission. 


\section{Conclusion}

As we know, the system PAPR will be impacted by a different number of sub-carriers in optical OFDM access systems. In this article, 8QAM-OFDM optical access system has been set up by simulation, including 8QAMOFDM optical signals generation, transmission and reception. The CCDF of two types of 8QAM-OFDM signals with 16, 32, 64, 128, 256, 512 sub-carriers are measured and analyzed. The results show that, as the number of sub-carriers increases, the value of PAPR rises. If the number of sub carriers is 16 , the PAPR value of two types of 8QAM-OFDM optical signals will be smaller than $5.2 \mathrm{~dB}$ at CCDF $=10^{-2}$. When the number of sub-carriers is 512, the PAPR value of two types of 8QAM-OFDM optical signals are less than $5.3 \mathrm{~dB}$ at CCDF $=10^{-2}$. Hence, choosing the optimal number of sub-carriers is essential for optical OFDM access systems application in reality.

\section{Acknowledgements}

This work is partially supported by the National Natural Science Foundation of China (No. 61107064), Innovation Program of Shanghai Municipal Education Commission (No. 15ZZ101), Leading Academic Discipline Project of Information and Communication Engineering (No. XXKZD1605), School Foundation (No.

EGD14XQD01) of Shanghai Polytechnic University, College Students' Science and Technology Innovation Project of Shanghai Polytechnic University (No. 2016-xjkj-063), and College Student Innovation Activity Plan in Shanghai (No. 2013-sj-cxjh-028).

\section{References}

[1] Shao, Y., Wang, Y. and Chi, N. (2013) 60-Ghz Rof System with Low Papr 16QAM-OFDM Downlink Using Pts Segmentation. IEEE Photonics Technology Letters, 25, 855-858. http://dx.doi.org/10.1109/LPT.2013.2252425

[2] Shao, Y., Chi, N., Fan, J. and Fang, W. (2012) Generation of 16-QAM-OFDM Signals Using Selected Mapping Method and Its Application in Optical Millimeter-Wave Access System. IEEE Photonics Technology Letters, 24, 13011303. http://dx.doi.org/10.1109/LPT.2012.2202387

[3] Shao, Y. (2016) Papr Reduction and Receiver Sensitivity Improvement in 16QAM-OFDM Rof System Using Dmt Modulation and Btn-Ps Technique. Optics \& Laser Technology, 77, 59-63. http://dx.doi.org/10.1016/j.optlastec.2015.08.013

[4] Ye, C., Li, Z., Jiang, T., Ni, C. and Qi, Q. (2014) Papr Reduction of oQAM-OFDM Signals Using Segmental Pts Scheme with Low Complexity. IEEE Transactions on Broadcasting, 60, 141-147. http://dx.doi.org/10.1109/TBC.2013.2282732

[5] Zhou, J. and Qiao, Y. (2015) Low-Papr Asymmetrically Clipped Optical ofdm for Intensity-Modulation/Direct-Detection Systems. IEEE Photonics Journal, 7, 1-8. http://dx.doi.org/10.1109/jphot.2015.2430843

[6] Luo, R., Li, R., Dang, Y., Yang, J. and Liu, W. (2015) Two Improved Slm Methods for Papr and Ber Reduction in ofdm-rof Systems. Optical Fiber Technology, 21, 26-33. http://dx.doi.org/10.1016/j.yofte.2014.07.007

[7] Li, X. and Gao, H. (2012) Study on PAPR of Single Carrier FDMA Signal in LTE Uplink. Communications Technology, 45, 41-43.

[8] Kuribara, H. and Tadokoro, S. (2013) Pilot-Aided Side Information Detection in Slm-Based Ofdm Systems. IEEE Transactions on Wireless Communications, 12, 3140-3147. http://dx.doi.org/10.1109/TWC.2013.061713.120280

[9] Hu, W.W., Li, C.P. and Chen, J.C. (2012) Peak Power Reduction for Pilot-Aided Ofdm Systems with Semi-Blind Detection. IEEE Communications Letters, 16, 1056-1059. http://dx.doi.org/10.1109/LCOMM.2012.050412.120482

[10] Lee, J., Lou, H.L., Toumpakaris, D. and Cioffi, J.M. (2006) Snr Analysis of Ofdm Systems in the Presence of Carrier Frequency Offset for Fading Channels. IEEE Transactions on Wireless Communications, 5, 3360-3364. http://dx.doi.org/10.1109/TWC.2006.256956 


\section{Submit or recommend next manuscript to SCIRP and we will provide best service for you:}

Accepting pre-submission inquiries through Email, Facebook, LinkedIn, Twitter, etc.

A wide selection of journals (inclusive of 9 subjects, more than 200 journals)

Providing 24-hour high-quality service

User-friendly online submission system

Fair and swift peer-review system

Efficient typesetting and proofreading procedure

Display of the result of downloads and visits, as well as the number of cited articles

Maximum dissemination of your research work

Submit your manuscript at: http://papersubmission.scirp.org/ 